\title{
Substantial Overlap Between Factors Predicting Symptoms of Depression and Burnout Among Medical Interns
}

\author{
Lisa S. Rotenstein, MD, MBA ${ }^{1,2}$, Zhuo Zhao, $M A, M S^{3,4}$, Douglas A. Mata, MD, MPH' \\ Constance Guille, MD, MSCR 6 , and Srijan Sen, MD, $P h D^{3,4}$
}

\begin{abstract}
${ }^{1}$ Harvard Medical School, Boston, MA, USA; ${ }^{2}$ Department of Medicine, Brigham and Women's Hospital, Boston, MA, USA; ${ }^{3}$ Molecular and Behavioral Neuroscience Institute, University of Michigan, Ann Arbor, MI, USA; ${ }^{4}$ Department of Psychiatry, University of Michigan, Ann Arbor, MI, USA; ${ }^{5}$ Department of Pathology, Memorial Sloan Kettering Cancer Center, New York, NY, USA; ${ }^{\circ}$ Department of Psychiatry and Behavioral Sciences, Medical University of South Carolina, Charleston, SC, USA.
\end{abstract}

J Gen Intern Med 36(1):240-2

DOI: $10.1007 / \mathrm{s} 11606-020-05664-\mathrm{x}$

(c) Society of General Internal Medicine 2020

\section{INTRODUCTION}

Medical professionals are at elevated risk of both depression and burnout. Major depressive disorder, which has standardized diagnostic criteria, has traditionally been attributed to a combination of personal and job-related factors, while burnout has been conceptualized as primarily a job-related stress phenomenon. ${ }^{1}$ Evidence on whether potential predisposing individual and job-related risk factors differ between the two syndromes is lacking. ${ }^{2}$ Further, there is disagreement as to whether these two syndromes represent the same phenomenon or are distinct entities. This prospective cohort study used validated survey instruments to examine whether predictors of depressive symptoms (DS) and burnout differed in medical interns, a population previously shown to be at high risk for both syndromes.

\section{METHODS}

As part of the Intern Health Study, 4996 training physicians starting their internship in 2017 were contacted 2 months prior to residency. $57.3 \%(n=2865)$ completed online surveys at baseline and again at 3,6,9, and 12 months of their intern year. $^{3}$ (DS) were measured with the 9-item Patient Health Questionnaire a validated screening instrument for major depression that can also be used to quantify DS severity. Emotional exhaustion (EE) and depersonalization (DP) were measured with the 9-item abbreviated Maslach Burnout Inventory. Workload and learning environment satisfaction were assessed with a residency program evaluation questionnaire (see Table 1 for all survey instruments used and their timing).

Because program-level variables were examined, only programs with a minimum of three interns completing at least one

Received December 5, 2019

Revised December 5, 2019

Accepted January 8, 2020

Published online February 5, 2020 of four follow-up surveys were included. Associations between demographic, individual, and workplace variables and DS, EE, and DP scores were examined in univariate and multivariate linear regression models. Effect sizes attributable to individual versus workplace factors were summed to quantify the proportion of variation in outcomes attributable to each. Analyses were performed using R version 3.6.1. Statistical tests were 2-sided with a significance threshold of $P<0.05$.

\section{RESULTS}

$54.2 \%$ ( $n=1552)$ of 2865 respondents met the inclusion criteria for this analysis. Included subjects did not differ from excluded subjects in DS, EE, or DP scores (data not shown, $\mathrm{p}>0.05$ for all comparisons). Subjects matched to residency programs at 68 institutions, including $32.8 \%$ to internal medicine, $16.3 \%$ to pediatrics, and $9.1 \%$ to emergency medicine. The mean age was 27.5 years (IQR 26-28), 51.7\% (803/1552) were women, and $37.5 \%$ (580/1552) were part of a couple.

There was substantial overlap between factors associated with DS and factors associated with EE or DP (Table 2). Of personal factors, female sex, history of depression, increased neuroticism score, increased early family environment score, single marital status, and lack of children were associated with higher levels of DS, EE, and DP. Of workplace factors, increased workload and learning environment satisfaction scores were associated with lower DS, EE, and DP.

Multivariate models including all six personal factors and both composite workplace factors as predictors explained $33.2 \%, 31.9 \%$, and $35.5 \%$ of the variance in DS, EE, and DP, respectively. Individual factors accounted for $67.8 \%$, $68.5 \%$, and $57.4 \%$ of the explained variance in DS, EE, and $\mathrm{DP}$, respectively.

\section{DISCUSSION}

While previous work has posited that burnout is distinct from depression and more influenced by job-related factors, ${ }^{1}$ our results suggest substantial overlap between the two 
Table 1 Questions and Instruments Employed in 2017 Intern Health Study

\begin{tabular}{|c|c|c|c|c|c|c|}
\hline Question/instrument & Citation & Baseline & $\begin{array}{l}3 \\
\text { months }\end{array}$ & $\begin{array}{l}6 \\
\text { months }\end{array}$ & $\begin{array}{l}9 \\
\text { months }\end{array}$ & $\begin{array}{l}12 \\
\text { months }\end{array}$ \\
\hline Age & & $\mathrm{x}$ & & & & \\
\hline Gender (multiple choice) & & $\mathrm{x}$ & & & & \\
\hline Ethnicity (multiple choice) & & $\mathrm{x}$ & & & & \\
\hline Sexual orientation (multiple choice) & & $\mathrm{x}$ & & & & \\
\hline Specialty (multiple choice) & & $\mathrm{x}$ & & & & \\
\hline Marital status (multiple choice) & & $\mathrm{x}$ & & & & \\
\hline Living with a significant other? (Y/N) & & $\mathrm{x}$ & & & & \\
\hline Self-reported history of depression $(\mathrm{Y} / \mathrm{N})$ & & $\mathrm{x}$ & & & & \\
\hline Parenting status $(\mathrm{Y} / \mathrm{N})$ & & $\mathrm{x}$ & & & & \\
\hline Weekly duty hours (number entry) & & $\mathrm{x}$ & $\mathrm{x}$ & $\mathrm{x}$ & $\mathrm{x}$ & $\mathrm{x}$ \\
\hline PHQ-9 & $\begin{array}{l}\text { Kroenke K, Spitzer RL, Williams JB. The } \\
\text { PHQ-9: validity of a brief depression severity } \\
\text { measure. J Gen Intern Med. } \\
\text { 2001;16(9):606-613. }\end{array}$ & $\mathrm{x}$ & $\mathrm{x}$ & $\mathrm{x}$ & $\mathrm{x}$ & $\mathrm{x}$ \\
\hline 9-item Maslach Burnout Inventory & $\begin{array}{l}\text { Maslach C, Jackson SE, Leiter MP. Maslach } \\
\text { Burnout Inventory Manual. 4th ed. Menlo Park: } \\
\text { CA: Mind Garden Inc; 2016. }\end{array}$ & $\mathrm{x}$ & & $\mathrm{x}$ & & \\
\hline 14-item Neuroticism Questionnaire & $\begin{array}{l}\text { Costa Jr PT, McCrae RR. Stability and change } \\
\text { in personality assessment: the revised NEO } \\
\text { Personality Inventory in the year } 2000 \text {. J Pers } \\
\text { Assess. 1997;68(1):86-94. }\end{array}$ & $\mathrm{x}$ & & & & \\
\hline 13-item Early Life Stress Questionnaire & $\begin{array}{l}\text { Taylor SE, Way BM, Welch WT, Hilmert CJ, } \\
\text { Lehman BJ, Eisenberger NI. Early family } \\
\text { environment, current adversity, the serotonin } \\
\text { transporter promoter polymorphism, and } \\
\text { depressive symptomatology. Biol Psychiatry. } \\
\text { 2006;60(7):671-676. }\end{array}$ & $\mathrm{x}$ & & & & \\
\hline Residency Evaluation Questionnaire & $\begin{array}{l}\text { Seelig CB, DuPre CT and Adelman HM: } \\
\text { Development and Validation of a Scaled } \\
\text { Questionnaire for Evaluation of Residency } \\
\text { Programs. SMJ (1995): } 88 ; 745-750\end{array}$ & & & & & $\mathrm{x}$ \\
\hline
\end{tabular}

Table 2 Univariate relationships between personal factors, workplace factors, and each of PHQ score, emotional exhaustion, and depersonalization.

\begin{tabular}{|c|c|c|c|c|}
\hline Predictors of PHQ-9 Score at 6 Months & Slope & LCI & UCI & $P$ \\
\hline \multicolumn{5}{|l|}{ Personal Factors } \\
\hline Sex (Female vs. Male) & 1.25 & 0.72 & 1.78 & $<0.0001$ \\
\hline History of Depression (Yes vs. No) & 2.67 & 2.15 & 3.18 & $<0.0001$ \\
\hline Part of Couple (Yes vs. No) & -0.71 & -1.26 & -0.17 & 0.01 \\
\hline Children (Yes vs. No) & -0.79 & -1.84 & 0.26 & 0.14 \\
\hline Baseline Neuroticism Score & 0.24 & 0.22 & 0.27 & $<0.0001$ \\
\hline Baseline Early Family Environment Score & 0.12 & 0.09 & 0.15 & $<0.0001$ \\
\hline \multicolumn{5}{|l|}{ Workplace Factors } \\
\hline Workload Satisfaction & -2.21 & -2.62 & -1.80 & $<0.0001$ \\
\hline Learning Environment Satisfaction & -2.13 & -2.63 & -1.63 & $<0.0001$ \\
\hline Predictors of EE Score at 6 Months & Slope & LCI & UCI & $\mathbf{P}$ \\
\hline \multicolumn{5}{|l|}{ Personal Factors } \\
\hline Sex (Female vs. Male) & 0.42 & -0.08 & 0.93 & 0.10 \\
\hline History of Depression (Yes vs. No) & 1.61 & 1.11 & 2.11 & $<0.0001$ \\
\hline Part of Couple (Yes vs. No) & -0.68 & -1.19 & -0.16 & 0.01 \\
\hline Children (Yes vs. No) & -1.90 & -2.89 & -0.90 & $<0.0001$ \\
\hline Baseline Neuroticism Score & 0.17 & 0.14 & 0.20 & $<0.0001$ \\
\hline Baseline Early Family Environment Score & 0.09 & 0.06 & 0.11 & $<0.0001$ \\
\hline \multicolumn{5}{|l|}{ Workplace Factors } \\
\hline Workload Satisfaction & -2.13 & -2.53 & -1.73 & $<0.0001$ \\
\hline Learning Environment Satisfaction & -2.27 & -2.75 & -1.79 & $<0.0001$ \\
\hline Predictors of DP Score at 6 Months & Slope & LCI & UCI & $\mathbf{P}$ \\
\hline \multicolumn{5}{|l|}{ Personal Factors } \\
\hline Sex (Female vs. Male) & -1.04 & -1.61 & -0.48 & $<0.0001$ \\
\hline History of Depression (Yes vs. No) & 0.89 & 0.32 & 1.46 & $<0.0001$ \\
\hline Part of Couple (Yes vs. No) & -0.77 & -1.34 & -0.20 & 0.01 \\
\hline Children (Yes vs. No) & -1.11 & -2.23 & 0.00 & 0.05 \\
\hline Baseline Neuroticism Score & 0.12 & 0.09 & 0.15 & $<0.0001$ \\
\hline Baseline Early Family Environment Score & 0.07 & 0.04 & 0.11 & $<0.0001$ \\
\hline \multicolumn{5}{|l|}{ Workplace Factors } \\
\hline Workload Satisfaction & -1.66 & -2.11 & -1.21 & $<0.0001$ \\
\hline Learning Environment Satisfaction & -2.07 & -2.61 & -1.53 & $<0.0001$ \\
\hline
\end{tabular}


syndromes. In our sample of training physicians, there was almost perfect overlap among the factors associated with DS and those associated with EE and DP. Further, the balance of workplace and individual factors influencing burnout components was qualitatively similar to those influencing DS. While novel in medicine, these findings are consistent with work in other populations showing strong qualitative and quantitative symptom overlap between burnout and depression. ${ }^{4}$

Efforts to address burnout have predominantly focused on altering physicians' relationships with their work environments. Our findings show that individual factors play a similarly large role in determining burnout as they do depression and suggest that individual-level prevention and treatment strategies should be explored to reduce both burnout and DS.

Corresponding Author: Lisa S. Rotenstein, MD, MBA; Department of Medicine Brigham and Women's Hospital, 75 Francis Street, Boston, MA, USA (e-mail: lrotenstein@Partners.org).
Conflict of Interest: The authors report no conflicts of interest.

\section{REFERENCES}

1. Maslach C, Schaufeli WB, Leiter MP. Job Burnout. Annu Rev Psychol. 2001;52(1):397-422. doi:https://doi.org/10.1146/annurev.psych.52.1. 397

2. Bianchi R, Truchot D, Laurent E, Brisson R, Schonfeld IS. Is burnout solely job-related? A critical comment. Scand J Psychol. 2014;55(4):357361. doi:https://doi.org/10.1111/sjop.12119

3. Sen S, Kranzler HR, Krystal JH, et al. A prospective cohort study investigating factors associated with depression during medical internship. Arch Gen Psychiatry. 2010. doi:https://doi.org/10.1001/archgenpsychiatry.2010.41

4. Bianchi R, Schonfeld IS, Laurent E. Is burnout separable from depression in cluster analysis? A longitudinal study. Soc Psychiatry Psychiatr Epidemiol. 2015;50(6):1005-1011. doi:https://doi.org/10. 1007/s00127-014-0996-8

Publisher's Note Springer Nature remains neutral with regard to jurisdictional claims in published maps and institutional affiliations. 